\title{
Portable Digital Video Instruction in Predoctoral Education of Child Behavior Management
}

\author{
James R. Boynton, D.D.S., M.S.; Lynn A. Johnson, Ph.D.; S.M. Hashim Nainar, B.D.S., \\ M.D.Sc.; Jan C.C. Hu, B.D.S., Ph.D.
}

Abstract: The goals of this exploratory study were to determine students' assessment of portable digital video instruction (using the Apple ${ }^{\circledR} \mathrm{iPod}\left({ }^{\circledR}\right)$ and to compare examination performance among groups of predoctoral dental students who did and did not utilize portable digital video instruction as a supplement to a conventional pediatric behavior management lecture. Dental students received a one-hour lecture on communication with the parent and child patient as part of their regular sophomore pediatric dentistry curriculum. Digital audio and digital video versions of this lecture were made available to all 113 students in the class. Eleven student volunteers were loaned portable digital video players (the iPod) containing the lecture for a two-week period. Upon completion of the study period, the entire class participated in an anonymous fifteen-minute post-intervention written assessment including a thirteen-item examination covering lecture material. Students who had used the iPod to review the digital video lecture material favored this medium as a pedagogical instrument and as a group performed significantly better on the examination than those who had not reviewed the digital material $(p=0.034)$. In conclusion, portable digital instructional videos may be a useful educational methodology to help predoctoral dental students acquire knowledge in pediatric behavior management.

\begin{abstract}
Dr. Boynton is Clinical Assistant Professor, Department of Orthodontics and Pediatric Dentistry, University of Michigan School of Dentistry; Dr. Johnson is Associate Professor, Department of Periodontics and Oral Medicine, and Director of Dental Informatics, University of Michigan School of Dentistry; Dr. Nainar is Associate Professor, Division of Pediatric Dentistry, Department of Dentistry, Faculty of Medicine and Dentistry, University of Alberta, Edmonton, Alberta, Canada; and Dr. Hu is Professor and Director of Pediatric Dentistry, Department of Orthodontics and Pediatric Dentistry, University of Michigan School of Dentistry. Direct correspondence and requests for reprints to Dr. James R. Boynton, Department of Orthodontics and Pediatric Dentistry, School of Dentistry, 1011 North University Avenue, Ann Arbor, MI 48109-1078; 734-763-2331 phone; 734-615-7294 fax; jboynton@umich.edu.
\end{abstract}

Key words: dental education, Internet, pediatric dentistry, videotape recording, video recording, learning technology

Submitted for publication 7/19/06; accepted 12/7/06

$\mathrm{M}$ anagement of children in the dental office is an intricate balancing act involving the triad of child, parent/caregiver, and dentist. Good communication skills (both verbal and nonverbal) are necessary to provide dental care for children. Proper communication ensures that dentists can safely deliver treatment to their child patients, comply with legal and ethical issues involved with treating children, and contribute to a trusting relationship, thereby fostering care in the best interests of the child. It is, therefore, vital for predoctoral dental students to be taught how to successfully communicate with children and their caregivers.

Although some aspects of patient and caregiver communication can be intuitive, the ability to engage in effective verbal and nonverbal communication with children and their caregivers is a skill set that must be learned by predoctoral dental students. The inherent nature of behavior management, however, makes it a difficult task to learn and review using traditional educational methodologies. One cannot simply read about voice control and be expected to use it effectively. Whereas clinical dentistry skills are taught by means of lectures and preclinical simulations, communication and behavior management skills are typically taught only with lectures. Predoctoral dental students are then expected to apply these essential skills in the clinical setting without previous practice. It is, therefore, incumbent upon all concerned to best prepare these students for realworld interactions.

A dynamic lecture replete with actual, replicable verbal and nonverbal communication scenarios is an important first step to teach this skill set. Cognitive research indicates that long-term retention of concepts and facts communicated to learners in a lecture format requires activities that allow students to review and rehearse use of this newly acquired information after the initial presentation. ${ }^{1}$ Unfortunately, once a typical lecture is over, students often have little ability to appropriately review this material. For sophomore dental students, it may be 
several months to more than a year before they have opportunities to actually apply the lecture information in a patient care situation. The hypothesis tested in this pilot study was that supplementing a lecture presentation on effective verbal and nonverbal communication with children and their caregivers with an easily accessible audio-video recording of a faculty instructor modeling these techniques may aid students' acquisition of skills in this area.

Videos have been used in health education for decades. ${ }^{2}$ Many studies utilizing videos have focused on the substitution of a lecture with a video..$^{2-4}$ Supplementation of lectures by media such as lecture notes with group discussion, ${ }^{5}$ tapes, ${ }^{6}$ and more recently computer modules ${ }^{7}$ have also been described. The recent introduction of a portable digital video player (iPod) provides an educational tool wherein content can be provided to students over the Internet with relative ease. The mobility of the iPod allows for review of downloaded material at a time and location convenient for each student.

The objectives of this study, therefore, were to compare examination performance among groups of sophomore dental students who did and did not utilize portable digital video instruction (the iPod) to supplement a conventional pediatric behavior management lecture and to determine student assessment of digital video instruction.

\section{Methods}

Predoctoral dental students enrolled in a sophomore pediatric dentistry didactic course participated in our study. A one-hour lecture entitled "Communication with the Parent and the Child Patient" was delivered to these students as a normal part of the curriculum. Arrangements were made to have the lecture digitally recorded in audio-only and video versions. Apple Computer, Inc.'s digital audio/video player, the fifth-generation iPod, and its associated software program, iTunes ${ }^{\circledR}$, were used in the study. Digital versions of the lecture were made available to all the students via download from a secure iTunes website. The students were provided with options to review the downloaded lecture. They could watch the video version on a computer (desktop or laptop) or a digital portable player with video capabilities (video iPod), listen to the lecture on a computer (desktop or laptop) or a portable mp3 player (including iPod), or choose not to review the digital material. An announcement was made at the time of the lecture that a written test, based upon the material in this lecture, would be administered two weeks later. Students were informed that performance on this examination would not contribute toward their grade in the pediatric dentistry didactic course.

The experimental group was randomly selected using the following procedure. Prior to the lecture, volunteers were solicited to participate in the experimental group. The students were informed that, in the experimental group, each student would be loaned an iPod with video capabilities for a two-week period. The students were told that the lecture would be preloaded onto the iPods before distribution to the students in the experimental group. It was made explicit that all students in the experimental group were required to watch the video playback of lecture during the study period. Twenty-three students out of a total of 113 students volunteered to participate in the experimental group. From these twenty-three volunteers, eleven were randomly chosen to constitute the experimental group. The experimental sample size was arbitrarily determined based upon the number of iPods with video capabilities available for the experiment.

Two weeks after the lecture, the post-intervention written test was conducted. The test was of fifteen minutes duration and was anonymous in response. The test was comprised of three components. The first component consisted of four respondent characteristics. Students were asked to identify their approximate class rank (top 25 percent; middle 50 percent; bottom 25 percent), indicate previous experience with dentistry outside of dental school (e.g., worked/ assisted in a dental office), and indicate experience working with children (e.g., worked in daycare). The fourth portion asked students to indicate how they interacted with the lecture material: attended lecture, listened to the audio version of the lecture on a portable mp3 player, listened to the audio version of the lecture on the computer (desktop/laptop), watched video version of the lecture on video iPod, or watched video version of the lecture on the computer (desktop/laptop). The second component, the examination, consisted of thirteen questions that assessed student comprehension of the lecture material pertaining to key communication concepts pertinent to pediatric behavioral management. These items included five short-answer questions, seven bimodal (true/false) questions, and one multiple-choice question. One of the short-answer questions was linked to a short video played at the beginning of the test to depict a common dental student/child communication error. 
The third component consisted of statements that evaluated student usage and beliefs regarding digital media. Student response was measured on a fivepoint scale as follows: strongly agree $=5$; agree $=4$; neutral $=3$; disagree $=2$; strongly disagree $=1$.

Data were entered into Microsoft Excel and analyzed with SPSS version 11.1.01. This study was reviewed and considered exempt by the Health Sciences Institutional Review Board at the University of Michigan.

\section{Results}

One hundred and eight students out of a total of 113 participated in the post-intervention test. Eleven students reported reviewing the digital video lecture material using an iPod; one student listened to the digital audio version of the lecture on a portable mp3 player, four students listened to the digital audio version of the lecture directly on the computer, while one student watched the digital video lecture material on a computer. The remaining ninety-one students had not reviewed any of the available digital material.

Given the utilization of the digital media by the students during the brief duration of this study, only limited data analyses were performed. Despite low usage of digital material, students did report a preference for digital video material, with a special emphasis on videos of clinical procedures (Table 1). The number of respondents differs on each statement as some survey responses were left blank. Students who had used the iPods to review their digital video lecture material favored this medium as a pedagogical instrument (Table 2).

On the thirteen-question examination that assessed student comprehension of the lecture material, the eleven students who had watched the lecture video on iPods performed better (Mean=9.27; standard deviation=1.79) than the ninety-one students who did not use any digital material to review the lecture (Mean=7.87, standard deviation=2.07). A Student's $\mathrm{t}$-Test for independent means showed this difference to be statistically significant $(p=0.034$ ). The six students who reported that they used other digital methods of review had a mean score of 7.83 on the examination (standard deviation=2.04), which did not significantly differ from the mean for students who did not review the material. The difference in mean examination performance between the eleven students in the iPod group and those six students who used other digital methods of review was not statistically significant ( $p=.146$ ). No significant differences were found within these groups regarding class rank, previous experience with dentistry, and previous experience with children.

\section{Discussion}

This study explored the use of portable digital video instruction in teaching behavior management in pediatric dentistry. The novelty of a new technology doesn't necessarily justify its usage. ${ }^{8}$ The finding that students who reviewed the material using the iPod performed better on the examination than those that had not may suggest the validity of this technology's use in education. But this result is not unexpected. The iPod group was essentially exposed to the lecture twice, dramatically increasing time on task, so it was not a surprise they did better. Other studies have also found that students perform significantly better if traditional lectures are augmented with additional material. ${ }^{9,10}$ The finding that the difference in mean examination scores between the experimental group of eleven iPod students and those ninety-one students who did not review the material was statistically significant was somewhat unexpected, given the small sample size of the experimental group.

Support for the usage of digital dental educational materials is provided by the majority of the students in this study who agreed that they would like to have digital video educational materials made available, preferably in a portable format. Less than 7 percent of students said they would watch the VHS recording at the library, while 60 percent indicated they would download the lecture to an iPod if they had one (Table 1). Additional support for the use of digital video augmentation of lectures is provided by the experimental group of students who used the iPods to review their digital video lecture material. These students overwhelmingly favored this medium as a pedagogical instrument (Table 2). All felt this method was more effective than paper notes to review, partially validating the reason this lecture was chosen for the pedagogical experiment. Ten of eleven students felt the iPod review helped them do better on the examination, and ten of eleven felt they picked up new information that they had missed the first time. The finding that nine out of eleven students felt they will communicate better with children and their parents after the review is of particular importance given the subject. Communication delivered confidently is of utmost importance when dealing with both parents 
Table 1. Online video assessment

\begin{tabular}{|c|c|c|c|c|c|c|}
\hline & $N$ & $\begin{array}{l}\text { Strongly } \\
\text { Disagree }\end{array}$ & Disagree & Neutral & Agree & $\begin{array}{l}\text { Strongly } \\
\text { Agree }\end{array}$ \\
\hline $\begin{array}{l}\text { If I had a video iPod, I would have downloaded } \\
\text { the lecture to it. }\end{array}$ & 95 & $13(13.7 \%)$ & $10(10.5 \%)$ & $15(15.8 \%)$ & $38(40.0 \%)$ & $19(20.0 \%)$ \\
\hline $\begin{array}{l}\text { I wish all lectures were video recorded and } \\
\text { available online. }\end{array}$ & 101 & $6(5.9 \%)$ & $8(7.9 \%)$ & $12(11.9 \%)$ & $46(45.5 \%)$ & $29(28.7 \%)$ \\
\hline $\begin{array}{l}\text { If the lecture were only available on a VHS tape } \\
\text { at the library, I would still go there and check } \\
\text { out the video. }\end{array}$ & 105 & $55(52.4 \%)$ & $31(29.5 \%)$ & $12(11.4 \%)$ & $7(6.7 \%)$ & $0(0 \%)$ \\
\hline $\begin{array}{l}\text { Video content is most important for basic } \\
\text { science courses. }\end{array}$ & 102 & $4(3.9 \%)$ & $27(26.5 \%)$ & $31(30.4 \%)$ & $26(25.5 \%)$ & $14(13.7 \%)$ \\
\hline $\begin{array}{l}\text { Video content is most important for diagnosis } \\
\text { and treatment planning (pathology, radiology, etc.). }\end{array}$ & 103 & $3(2.9 \%)$ & $7(6.8 \%)$ & $32(31.1 \%)$ & $44(42.7 \%)$ & $17(16.5 \%)$ \\
\hline $\begin{array}{l}\text { Video content is most important for technical } \\
\text { dentistry (how-to of cavity preps, crowns, etc.). }\end{array}$ & 104 & $4(3.8 \%)$ & $8(7.7 \%)$ & $17(16.3 \%)$ & $39(37.5 \%)$ & $36(34.6 \%)$ \\
\hline
\end{tabular}

Note: $\mathrm{N}$ refers to the total number of students responding to each statement. The numbers in each cell refer to the total number of students who indicated each response. The percentage (in parentheses) is the percentage of the total number of respondents for each statement.

Table 2. Perceived effectiveness of iPod with video playback

\begin{tabular}{|c|c|c|c|c|c|c|}
\hline & $N$ & $\begin{array}{l}\text { Strongly } \\
\text { Disagree }\end{array}$ & Disagree & Neutral & Agree & $\begin{array}{l}\text { Strongly } \\
\text { Agree }\end{array}$ \\
\hline $\begin{array}{l}\text { The digital media I used to review this material } \\
\text { was more effective than using paper notes. }\end{array}$ & 11 & $0(0 \%)$ & $0(0 \%)$ & $0(0 \%)$ & $5(45.5 \%)$ & $6(54.5 \%)$ \\
\hline $\begin{array}{l}\text { I think I did better on this test because I used the } \\
\text { digital media to review the material. }\end{array}$ & 11 & $0(0 \%)$ & $0(0 \%)$ & $1(9.1 \%)$ & $7(63.6 \%)$ & $3(27.3 \%)$ \\
\hline $\begin{array}{l}\text { I will do better communicating with children and } \\
\text { their parents after reviewing the digital material. }\end{array}$ & 11 & $0(0 \%)$ & $0(0 \%)$ & $2(18.2 \%)$ & $6(54.5 \%)$ & $3(27.3 \%)$ \\
\hline I picked up new information during the digital & 11 & $0(0 \%)$ & $0(0 \%)$ & $1(9.1 \%)$ & $8(72.7 \%)$ & $2(18.2 \%)$ \\
\hline
\end{tabular}

review that I had missed during the lecture.

Note: $\mathrm{N}$ refers to the total number of students in the experimental group. The numbers in each cell refer to the total number of students who indicated each response. The percentage (in parentheses) is the percentage of the total number of respondents for each statement.

and children. If dental students feel more confident, perhaps this level of comfort will positively affect their interactions with children and parents.

Given the excitement associated with the adoption of evolving information technology (IT), this study provided thought-provoking data with regard to IT application in an educational setting. Of the ninety-seven students not chosen to participate in the experimental group, only six (6.2 percent) reported reviewing the digital educational material that had been made available during the two-week study duration. Several factors might have contributed to this low utilization of the provided educational re- sources. First, the examination was anonymous and voluntary. It is possible that if this examination contributed to the students' grade in the course, greater numbers of students might have reviewed the available digital material. Perhaps the duration of time between the lecture and the assessment influenced participation: students may not have felt the need to review something they had just seen two weeks prior. The lighter nature of this lecture in comparison to other course content in the challenging secondyear dentistry curriculum, as well as its timing (the lecture was given five months prior to students' first clinical pediatric dentistry rotation) might also have 
influenced participation. In a study conducted by Brittain et al., review of server logs demonstrated that 60 percent of dental students participated in a pilot study of online availability of audio files with subjects such as biochemistry and histology. ${ }^{11}$ These findings suggest that students may be more likely to use electronic educational materials if they perceive a pressing need.

There are a number of limitations to this exploratory study. Because iPods are relatively expensive, only eleven were available, which led to a low number of students in the experimental group. This is a clear shortcoming that limits the statistical power of the study. Although the experimental and control groups did not differ significantly in terms of class rank, experience with children, or experience with dentistry, the lack of a pre-test to assess students' baseline knowledge is another limitation. Another limitation is that the assignment of students to the study groups was not a completely random process. The subject recruitment strategy was to solicit volunteers who were willing to participate in the study and randomly select participants from the volunteers. This resulted in eleven students being selected randomly from among twenty-three volunteers out of a class of 108 .

The evaluation tool itself is limited: the examination was evaluated for appropriate content, but no other measures of validity were made. And one could argue that the use of a written examination to test acquisition of verbal and nonverbal communication skills could be inappropriate. Efforts were made to make the written examination as applicable as possible, with the inclusion of video and situationalbased communication questions. But for the same reasons that written review of this material is insufficient, written evaluation may also be inappropriate. Though statistically significant, it is unknown if the experimental group's higher scores on the examination will contribute to enhancing the students' clinical performance. And the fact that the test did not contribute to the students' grade in the course may have influenced the students' level of motivation to perform optimally on the examination.

Further study of this technology is indicated. Future studies may expand the number of students using digital video (either portable or otherwise), expand the subject matter covered, or expand the type of video offered (video-recorded lectures vs. clinical vignettes, for example). The efficacy of the use of digital audio files (audio recordings of lectures or podcasts) in dental education has also yet to be determined.

\section{Conclusion}

The findings from this exploratory study suggest that portable digital instructional videos may be a useful educational methodology to help predoctoral dental students acquire knowledge in pediatric behavior management.

\section{Acknowledgments}

This study was supported by Dental Informatics as well as the Dr. Samuel Harris Collegiate Professorship at the University of Michigan. We thank Daniel Bruell and Keary Campbell for their assistance with the technical production of the digital educational material used in this study.

\section{REFERENCES}

1. Gage NL, Berliner DC. Educational psychology. 3rd ed. Boston: Houghton Mifflin, 1984.

2. Paegle RD, Wilkinson EJ, Donnelly MB. Videotaped vs traditional lectures for medical students. Med Educ 1980; 14(6):387-93.

3. Soloman DJ, Ferenchick GS, Laird-Fick HS, Kavanaugh $\mathrm{K}$. A randomized trial comparing digital and live lecture formats. BMC Med Educ 2004;4:27.

4. Chen MS, Horrocks EN, Evans RD. Video versus lecture: effective alternatives for orthodontic auxiliary training. $\mathrm{Br}$ J Orthod 1998;25(3):191-5.

5. Johnson JP, Mighten A. A comparison of teaching strategies: lecture notes combined with structured group discussion versus lecture only. J Nurs Educ 2005;44(7): 319-22.

6. White LD. Direct tape access as an adjunct to learning. Nurs Res 1975;24(4):295-8.

7. Gupta B, White DA, Walmsley AD. The attitudes of undergraduate students and staff to the use of electronic learning. Br Dent J 2004;196(8):487-92.

8. Spickard A, Alrajeh N, Cordray D, Gigante J. Learning about screening using an online or live lecture: does it matter? J Gen Intern Med 2002;17(7):540-5.

9. Gilbart M, Hutchinson C, Cusimano M, Regehr G. A computer-based trauma simulator for teaching trauma management skills. Am J Surg 2000;179:223-8.

10. Fouad AF, Burleson JA. Effectiveness of an endodontic diagnosis computer simulation program. J Dent Educ 1997;61(3):289-95.

11. Brittain S, Glowacki P, Van Ittersum J, Johnson L. Podcasting lectures: formative evaluation strategies helped identify a solution to a learning dilemma. EDUCAUSE Quarterly 2006;29(3). 